\title{
Useful Parameters for the Design of Laser Pointer Interaction Techniques
}

\author{
Choon Hong Peck \\ Human Computer Interaction Institute \\ Carnegie Mellon University \\ Pittsburgh, PA 15213 \\ chpeck@andrew.cmu.edu
}

\begin{abstract}
This paper reports on some fundamental parameters for the design of wall-based laser pointer interaction techniques. Ten users participated in this study and their laser points were tracked and recorded by a computer. The data collected were then processed and statistically analyzed to provide parameters like the size of the dwell of a laser point, the time taken to acquire a target and the time required to determine a dwell on a target. These numbers are needed when designing interaction techniques that use a laser pointer.
\end{abstract}

\section{KEYWORDS}

Laser pointer, remote mouse, interaction technology, novel input techniques, Pebbles.

\section{INTRODUCTION}

With the widespread use of projection screens and laser pointers, there has been much research in the area of projection-based multi-user systems using laser pointers as interaction devices (e.g. [1, 2]). However, partially due to the lack of actual user data on the usage of the laser pointing devices, many of these systems are unsuccessful in their implementation. This study aims to discover some of the more fundamental parameters of a users laser pointing and, as a result, aid in the design of more usable laser interaction techniques. Specifically, we hope to discover answers to some of problems related to selecting, clicking and dragging widgets on a projection screen using a laser pointer. The issues related to this study includes not having a button (like a mouse) on the laser pointer to signal a location, laser point wiggles due to the inability to steadily hold a laser pointer, and being unable to control the locations of the laser point when the beam goes on and off. Future interaction techniques will need to take these into account. This study is a part of the Pebbles project at Carnegie Mellon University [3].

\section{EXPERIMENTAL SETUP}

A camera was placed 3 inches behind a piece of tracing paper, facing a target, which is a small dot with crosshairs, indicated on the tracing paper (Figure 1). A computer program then grabs frames from the camera with $320 \times 240$ resolution at a rate of $18-20 \mathrm{fps}$ and tracks the location of the laser.

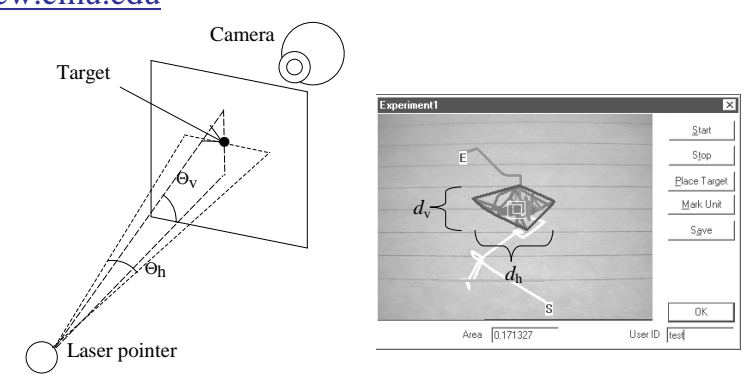

Figure 1. Experimental Setup, and trace of one subject.

For each trial, the user is asked to aim at the target indicated on the tracing paper using the laser pointer. The user hears a beep from the computer when he/she has acquired the target. The user then holds the laser point as steadily as possible on the target for 3 seconds. A second beep then signals the user to turn off the laser.

The computer program records each trial in three phases. The acquisition phase records the entry trail of the laser as the user moves towards the target. The second phase records the dwell of the laser point on the target. The third phase records the laser's exit trail.

Each user was requested to perform 8 trials. Four of the trials are conducted with a conventional small laser pointer and the remaining trials were conducted using the Symbol SPT 1700 handheld device, which is like a Palm Pilot with a built in laser. Out of the 4 trials using the conventional laser pointer, in 2 of the trials the user was 5 feet from the target and the in the other 2 the user was 10 feet away. All trials using the conventional laser pointer were conducted with the user's dominant hand. With the SPT 1700, the user did one trial each at 5 feet and 10 feet with each hand. Studying the non-dominant hand will provide parameters for designing interaction techniques that require the user to hold the handheld and operate the laser with the non-dominant hand while leaving the dominant hand free to write on the handheld device.

\section{RESULTS}

Ten participants between the ages of 20 to 23 took part in this user study, 4 women and 6 men. Prior to the experiment, the users filled out a questionnaire on their experience level and frequency of using a laser pointer. The mean score of the users were, on a scale of 1 to 5 , 
2.6 for experience and 1.8 for frequency of usage (where $1=$ none and $5=\mathrm{a}$ lot).

Table 1.1. Angle and diameter deviations (Laser Pointer)

\begin{tabular}{|l|l|l|}
\hline & $5 \mathrm{ft}$ & $10 \mathrm{ft}$ \\
\hline$\theta_{\mathrm{h}}$ (degrees) & $0.570 \pm 0.167$ & $0.437 \pm 0.140$ \\
\hline$\theta_{\mathrm{v}}$ (degrees) & $0.419 \pm 0.119$ & $0.402 \pm 0.116$ \\
\hline$D_{\mathrm{h}}$ (inches) & $0.586 \pm 0.177$ & $0.916 \pm 0.294$ \\
\hline$D_{\mathrm{v}}$ (inches) & $0.439 \pm 0.124$ & $0.843 \pm 0.243$ \\
\hline
\end{tabular}

Table 1.2. Angle and diameter deviations (SPT 1700)

\begin{tabular}{|c|l|l|l|l|}
\hline \multirow{2}{*}{} & \multicolumn{2}{|l|}{ SPT Dominant } & \multicolumn{2}{l|}{ SPT Non-Dom. } \\
\cline { 2 - 5 } & $5 \mathrm{ft}$ & $10 \mathrm{ft}$ & $5 \mathrm{ft}$ & $10 \mathrm{ft}$ \\
\hline Mean $\theta_{\mathrm{h}}$ (degrees) & 0.557 & 0.455 & 0.592 & 0.482 \\
\hline Standard Deviation & 0.153 & 0.153 & 0.162 & 0.143 \\
\hline Mean $\theta_{\mathrm{v}}$ (degrees) & 0.397 & 0.298 & 0.535 & 0.385 \\
\hline Standard Deviation & 0.088 & 0.073 & 0.277 & 0.151 \\
\hline Mean $d_{\mathrm{h}}$ (inches) & 0.583 & 0.951 & 0.620 & 1.010 \\
\hline Standard Deviation & 0.160 & 0.320 & 0.170 & 0.299 \\
\hline Mean $d_{\mathrm{v}}$ (inches) & 0.415 & 0.625 & 0.561 & 0.807 \\
\hline Standard Deviation & 0.093 & 0.152 & 0.290 & 0.316 \\
\hline
\end{tabular}

Table 2. Time to acquire target

\begin{tabular}{|c|l|l|l|l|l|l|}
\hline \multirow{2}{*}{ (seconds) } & \multicolumn{2}{|l|}{ Laser Pointer } & \multicolumn{2}{l|}{ SPT Dominant } & \multicolumn{2}{l|}{ SPT Non-Dom. } \\
\cline { 2 - 7 } & $5 \mathrm{ft}$ & $10 \mathrm{ft}$ & $5 \mathrm{ft}$ & $10 \mathrm{ft}$ & $5 \mathrm{ft}$ & $10 \mathrm{ft}$ \\
\hline Mean & 0.686 & 1.121 & 0.529 & 1.435 & 0.907 & 1.161 \\
\hline S.D. & 0.406 & 0.843 & 0.345 & 0.842 & 0.489 & 1.424 \\
\hline Max & 1.700 & 3.545 & 1.102 & 2.674 & 2.000 & 5.017 \\
\hline
\end{tabular}

Table 3. Convex hull area of dwell points

\begin{tabular}{|c|l|l|l|l|l|l|}
\hline \multirow{2}{*}{$\left(\right.$ inch $\left.^{2}\right)$} & \multicolumn{2}{|l|}{ Laser Pointer } & \multicolumn{2}{l|}{ SPT Dominant } & \multicolumn{2}{l|}{ SPT Non-Dom. } \\
\cline { 2 - 7 } & $5 \mathrm{ft}$ & $10 \mathrm{ft}$ & $5 \mathrm{ft}$ & $10 \mathrm{ft}$ & $5 \mathrm{ft}$ & $10 \mathrm{ft}$ \\
\hline Mean & 0.182 & 0.508 & 0.160 & 0.381 & 0.239 & 0.546 \\
\hline S.D. & 0.109 & 0.242 & 0.067 & 0.143 & 0.205 & 0.334 \\
\hline
\end{tabular}

\section{DISCUSSION}

People are not able to hold a laser pointer absolutely steady. Table 1.1 shows the diameter of the maximum jitter $\left(d_{\mathrm{h}} \& d_{\mathrm{v}}\right)$ and the angle of deviation $\left(\theta_{\mathrm{h}} \& \theta_{\mathrm{v}}\right)$ in both horizontal and vertical axes between the 2 distances for the conventional laser pointer averaged over the trials. We find that $\theta_{\mathrm{h}}$ at $10 \mathrm{ft}$ is significantly ( $p$ $<0.005)$ less than $\theta_{\mathrm{h}}$ at $5 \mathrm{ft}$ whereas there is no significant difference in $\theta_{v}$. We speculate that this reduction in $\theta_{\mathrm{h}}$ may be because the absolute distance of the deviation is larger and users can correct the position more easily when they can see the deviation more clearly. When we compared the $\theta_{\mathrm{h}}$ at $5 \mathrm{ft}$ against $\theta_{\mathrm{v}}$ at 5 $\mathrm{ft}$, we find that $\theta_{\mathrm{h}}$ is significantly greater $(p<0.001)$ than $\theta_{v}$. This result suggests that the shape of the laser dwell is more like a horizontal ellipse at $5 \mathrm{ft}$ and more circular at $10 \mathrm{ft}$. We have no theory for why this would happen.

For the Symbol SPT 1700 handheld device (Table 1.2), we find that $\theta_{\mathrm{h}}$ and $\theta_{\mathrm{v}}$ at $10 \mathrm{ft}$ are significantly $(p<0.05)$ less than $\theta_{\mathrm{h}}$ and $\theta_{\mathrm{v}}$ at $5 \mathrm{ft}$ for the dominant hand. However, we did not find any statistical difference $(p \approx$ $0.05)$ in both $\theta_{\mathrm{h}}$ and $\theta_{\mathrm{v}}$ between the distances for the non-dominant hand. This result implies that the user is able to correct the laser point more effectively at the further distance with his/her dominant hand but not so with his/her non-dominant hand. Also, the result suggests that users will generally produce a more circular drift using the SPT 1700. Thus, the physical design of the laser device impacts the performance.

What this means for a typical projection screen, in a small room where the user is $5 \mathrm{ft}$ from a $6 \mathrm{ft}$ wide screen, is that the size of the wiggle in the $\mathrm{x}$ and $\mathrm{y}$ axes will be about 10 and 7 pixels respectively. Standing 10 feet from a large $8 \mathrm{ft}$ wide screen, the wiggle will be about 12 pixels in both axes. This implies that widgets designed for laser interaction must be fairly big.

Comparing the time $(t)$ required to acquire the target (Table 2), we find that $t$ at $10 \mathrm{ft}$ is significantly ( $p<$ $0.01)$ greater than $t$ at $5 \mathrm{ft}$ for both devices using the dominant hand. To be relatively certain that the laser point is in the vicinity of an intended target, we have to track the laser point for at least 0.9 secs at $5 \mathrm{ft}$ and 1.4 secs at $10 \mathrm{ft}$, taking the maximum mean times.

We also find that the start and end points of the users' laser trials are typically not close to the target. Hence, the start and end points of the laser path are not good indications of the user's intention, unlike with a regular mouse. However, the moving average of the laser points can be a good indication of the user's locative intentions. The moving average of the dwell points over 1 second at $18 \mathrm{fps}$ is usually within 0.2 inches $(\approx 2$ pixels on a projection screen) from the target.

The implications of these numbers on the design of laser pointer interaction techniques are that to correctly track a user's dwell on a location to within 2 pixel accuracy, we have to track the laser for at least 0.9-1.4 seconds to wait for the user to get to where they want the beam to be, and then wait about another one second to get an accurate moving average, which will be within 2 pixels of the target point. This is a total of about 3 seconds to execute a selection. If start and end-point pair is desired (such as for a drag of an object to a new location), the location where the beam disappears cannot be used, the system must look for the first and last dwell-points.

\section{ACKNOWLEDGEMENTS}

The research reported here is supported in part by grants from DARPA and Symbol Technologies, Inc. This research was performed in part in connection with Contract number DAAD17-99-C-0061 with the U.S. Army Research Laboratory. Thanks to Brad Myers for help with this paper.

\section{REFERENCES}

1. Eckert, R.R. and Moore, J.A., "The Classroom of the 21st Century: The Interactive Learning Wall." SIGCHI Bulletin, 2000. 23(2): pp. 33-40.

2. Horn, G.A.V., "Proxima's new Ovation+ projection panels do up multimedia." Byte (on-line), 1995. http://www.byte.com/art/9501/sec12/art9.htm.

3. Myers, B.A., Stiel, H., and Gargiulo, R. "Collaboration Using Multiple PDAs Connected to a PC," in Proceedings CSCW'98: ACM Conference on Computer-Supported Cooperative Work. 1998. Seattle, WA: pp. 285-294. http://www.cs.cmu.edu/ pebbles. 